\title{
The patient, the OTC drug, and the pharmacist - an (in)separable triad? A critical analysis of self-medication
}

\author{
Camil E. VARI, Bianca-Eugenia ÖSZ, George JITCA, \\ Alexandra GROSAN, Mihai Ciprian STOICA \\ Pharmacology and Clinical Pharmacy Department, George Emil Palade University of Medicine, \\ Pharmacy, Science, and Technology, Târgu Mureș, Romania
}

\begin{abstract}
Self-medication can be defined as the use of over-the-counter medications, released at the patient's request. In order to be effective and to reduce the risk of side effects and iatrogenic accidents, their release should be accompanied by specialist advice, which is the prerogative of the pharmacist. Thus, self-medication requires a drug-patient-pharmacist relationship. This paper highlights some practical aspects of OTC medication. We also present some particular cases of medicines released under the OTC regime, but also of medicines that currently require a prescription, although they were initially released on request.
\end{abstract}

Keywords: OTC drug, pharmaceutical counseling, patient, iatrogenic risk

\section{INTRODUCTION}

Self-medication, according to the dictionary definition, is the consumption of medicines on one's own initiative, without a prescription. Obviously, such a process requires a minimum of general medical culture and correct information before the actual administration of the medicine(s) in question.

According to the legislation in force, medicines from the community pharmacy are issued either on the basis of a medical prescription (type P-RF prescription that is retained in the pharmacy, $\mathrm{P}-6 \mathrm{~L}-$ prescription valid for 6 months, special formulations for psychotropic drugs and narcotics), or on request, in the case of OTC medicines and food supplements [1]. In the media accessible to the general public (radio, television), advertising is allowed only for OTC medicines (and for food supplements, which are not medicines and, consequently, have a much more permissive registration and marketing regime than medicines; however, it is not the subject of this paper). For any medicine requiring a prescription, advertising may be made only in journals intended for health professionals [2]. Moreover, the current COVID-19 pandemic has, however, led to intense, indirect advertising of prescription drugs (azithromycin, dexamethasone, hydroxychloroquine, etc.) or which do not have market authorization in Romania for human use (ivermectin), through televised debates, with pros and cons, before they are (in)validated by clinical trials. However, on social networks, these drugs benefited from an aggressive promotion, which was later reflected in a massive 


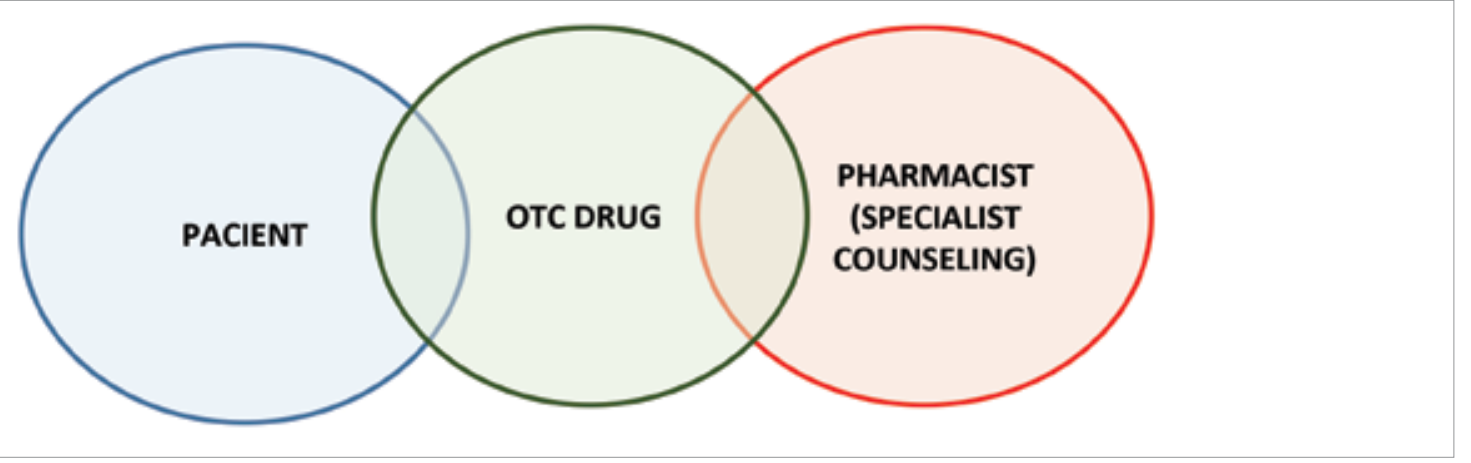

FIGURE 1. The three players involved in self-medication

demand from pharmacies, not always accompanied by the necessary and mandatory prescription (in which case the release from the pharmacy violated the legal rules imposed by orders of minister).

Furthermore, regarding the OTC drug, a few key issues need to be emphasized. Normally, self-medication should mean the release of a medicine on request, accompanied by the necessary advice provided by the pharmacist (method of administration, contraindications, possible side effects). Moreover, the advertising for such a medicine, according to the law, is accompanied by the statement: "This medicine can be dispensed without a prescription. It is recommended that you read the package leaflet or the information on the package carefully. In case of any side effects, talk to your doctor or pharmacist" (our translation) [3].

\section{THE RELATIONSHIP BETWEEN 3 PLAYERS: THE PATIENT, THE MEDICATION, AND THE PHARMACIST}

The proper use of over-the-counter medication involves the relationship between 3 players: the patient, the medication, and the pharmacist (Figure 1).

Any situation in which one of the 3 fundamental elements of self-medication is missing (patient, OTC medicine, pharmacist) can be the cause of severe dysfunctions to the detriment of the patient. Let us further analyze critically some such situations.

\section{Patient - OTC medicine}

The lack of the third element (pharmacist) implies the release (the correct term, in this case, is the purchase) of the medicine without being accompanied by specialized advice; it is a common case when the drug is obtained from the supermarket or drugstores (present at will, on the shelf, along with food supplements). Obviously, side effects may occur, even if they are mild or moderate. In addition, a number of contraindications can have severe consequences (e.g. the use of NSAIDs in the last trimester of pregnancy which may induce premature closure of the ductus arteriosus [4], with subsequent cardiopulmonary toxicity in the newborn; although, as stated by the leaflet, it would need to be explained by specialist staff.

\section{OTC drug - patient}

Although the lack of the patient in the equation may seem absurd, the situation can, unfortunately, be encountered in practice. It is the case that, in the pursuit of profit, the pharmacist convinces patients to purchase the OTC drugs that they do not need, based on the so-called associated recommendation. There are of course cases in which the recommendation of an OTC is welcome (a gastric protector in case of NSAID administration, a probiotic to restore the intestinal flora after antibiotic therapy, etc.) $[5,6]$. But the release of OTC drugs that the patient does not need (vitamins and minerals in the absence of a proven deficiency, various dietary supplements unnecessary in certain conditions - it is known that these products are not intended to treat any disease, but only complement a normal diet) is a process that forces the deontological limits of the profession.

Naturally, self-medication should be supervised by the pharmacist who takes note of the patient's need, informs him/ her about the dose to use, the interval of administration and possible side effects and directs the patient to the doctor in risk situations (vulnerable people or special populations): extreme ages (infants, children, elderly), particular physiological conditions (pregnancy, lactation), particular diet with consequences on oral absorption, conditions affecting 
the elimination pathways (liver or kidney failure), co-morbidities, drug interactions [7].

Some particular cases of drugs with OTC status will be presented below (or which previously had such status, but lost it as a result of pharmacovigilance reports).

\section{ACETYLSALICYLIC ACID}

Considered a common drug, acetylsalicylic acid is a widely used OTC drug, although the risks are not negligible. In analgesic or anti-inflammatory doses, the ulcerogenic effect is important, and the patient's anamnesis should be performed carefully (gastroduodenal ulcer) [8]. The possibility of worsening pre-existing asthma (aspirin-induced asthma) should also be assessed [9] and prohibited in children with viral infections (risk of Reye's syndrome) [10]. Even the use of low doses as an antiplatelet agent in the primary/ secondary prevention of myocardial infarction remains questionable in terms of risk/ benefit balance (in the absence of efficacy proven by aggregation tests and assessment of ulcerative/ hemorrhagic risk in sensitive patients) [11].

\section{COLD AND INFLUENZA PRODUCTS}

The administration of cold and influenza products (such as ibuprofen and pseudoephedrine) should be well-planned. NSAIDs have an ulcerative risk and may reduce the effectiveness of antihypertensive medication [12]; pseudoephedrine as alpha, beta adrenomimetic can induce high blood pressure, can increase heart rate and reduce the effects of some drugs (beta blockers, vasodilators) [13]. In addition, NSAIDs should never be given in the third trimester of pregnancy (risk of premature closure of ductus arteriosus) [4] and present a major risk of drug interactions by displacement from plasma proteins with coumarin anticoagulants (INR monitoring is required) and with sulphonylurea class of oral antidiabetics (risk of hypoglycemia, blood glucose should be monitored, even by the patient by rapid tests) [14].

\section{PARACETAMOL (ACETAMINOPHEN)}

Used correctly, paracetamol is a safe and effective drug, and can be administered even in special populations (newborns, pregnant women, infants). However, according to Paracelsus's "solo dosis facit venenum" paradigm, the dose taken at one time (a single high dose) exerts a dose-dependent hepatic toxicity via CYP450-dependent oxidation due to saturation of the two major metabolic pathways (glucurono- and sulfo-conjugation). This toxic pathway leads to the formation of one reactive and toxic metabolite - NAPQI ( $\mathrm{N}$-acetyl-p-benzoquinone-imine); this metabolite is detoxified by the intervention of reduced glutathione, therefore the antidote that can be used in extreme cases (acute liver necrosis with life threatening risk) is $\mathrm{N}$-acetylcysteine [15]. Also, the hepatic toxic risk of paracetamol is higher in chronic alcoholics or those with hepatopathies (chronic viral hepatitis, hepatic steatosis, elevated transaminases, concomitant hepatotoxic medication) [16].

\section{METAMIZOLE SODIUM (NORAMINOPHENAZONE SODIUM METHANESULFONATE, DIPYRONE)}

For a long time, metamizole sodium was an OTC drug widely used in Romania, even if in some countries it never obtained marketing authorization or was withdrawn (USA, Sweden, India, France etc.). At present, it requires a prescription that is retained by the pharmacy. The cause of this change was the relatively frequent cases of agranulocytosis, reported especially in northern Europe [17]. Although widely used as an analgesic and antipyretic, metamizole has not been reported in Romania for such an adverse reaction, but as a precaution, its release has been restricted.

\section{PROTON PUMP INHIBITORS (PANTOPRAZOLE)}

Frequently used in dyspeptic syndrome, heartburn, gastroesophageal reflux, and gastric hyperacidity, pantoprazole should be used for a limited time; if the patient's condition does not improve after 1-2 weeks, he/ she should be referred to a specialist (gastroenterologist). It should not be forgotten that proton pump inhibitors can mask the symptoms of gastric cancer and, therefore, delay the establishment of the correct diagnosis [18].

\section{VITAMIN PRODUCTS}

The use of vitamins in doses not exceeding daily recommended intake may be subject to release on request. However, a few remarks are needed: 
- some vitamins, used in high doses and in the long term can have unfavorable consequences (ascorbic acid alters urinary $\mathrm{pH}$ and promotes oxalic lithiasis [19]; high doses of pyridoxine (as well as deficiency) can cause polyneuritis [20];

- excessive use of pyridoxine during pregnancy (very high doses in the first trimester used in hyperemesis gravidarum continued in the last 2 trimesters may promote convulsions in the newborn by postpartum GABA deficiency [21]; pyridoxine may decrease the effectiveness of L-DOPA by promoting its peripheral decarboxylation (DOPA-decarboxylase or $\mathrm{L}$-aromatic aminoacid decarboxylase is a PLP-dependent enzyme) [22];

- excess of vitamin A has a teratogenic effect in pregnant women (risk category $\mathrm{X}$ according to
FDA). Vitamin A intake will be strictly monitored during pregnancy! [23]. On the contrary, other vitamins must be supplemented during pregnancy (folic acid decreases the risk of neural tube defects in the newborn) [24].

\section{CONCLUSIONS}

Self-medication facilitates the patient's access to medical services and can be a useful solution in treating mild ailments. However, OTC medicines may have side effects (some severe ones) and clear contraindications, so their release should always be accompanied by specialist advice; the most professionally qualified person to give advice on dosage, side effects, contraindications, and limits of administration is, undoubtedly, the pharmacist.

Conflict of interest: none declared Financial support: none declared

\section{REFERENCES}

1. ${ }^{* * *}$ Ordinul nr. $1602 / 2010$ pentru aprobarea Normelor privind clasificarea pentru eliberare a medicamentelor de uz uman

2. *** Ordin Nr. 194 din 23 februarie 2015 privind aprobarea Normelor pentru evaluarea şi avizarea publicităţii la medicamentele de uz uman

3. ${ }^{* * *}$ Codul de reglementare a conținutului audiovizual din 24 februarie 2011 (DECIZIE nr. 220/2011

4. Koren G, Florescu A, Costei AM, et al. Nonsteroidal antiinflammatory drugs during third trimester and the risk of premature closure of the ductus arteriosus: a meta-analysis. Ann Pharmacother. 2006 May;40(5):824-9.

5. Ibañez-Cuevas V, Lopez-Briz E, Guardiola-Chorro MT. NSAID induced Gastropathy Prevention Programme Group. Pharmacist intervention reduces gastropathy risk in patients using NSAIDs. Pharm World Sci. 2008 Dec;30(6):947-54.

6. Can M, Beşirbellioglu BA, Avci IY, et al. Prophylactic Saccharomyces boulardii in the prevention of antibioticassociated diarrhea: a prospective study. Med Sci Monit. 2006 Apr;12(4):PI19-22.

7. Bennadi D. Self-medication: A current challenge. J Basic Clin Pharm. 2013;5(1):19-23.

8. Lanas A, García-Rodríguez LA, Arroyo MT, et al. Risk of upper gastrointestinal ulcer bleeding associated with selective cyclo-oxygenase- 2 inhibitors, traditional non-aspirin nonsteroidal anti-inflammatory drugs, aspirin and combinations. Gut. 2006 Dec;55(12):1731-8.

9. Szczeklik A, Stevenson DD. Aspirin-induced asthma: advances in pathogenesis, diagnosis, and management. J Allergy Clin Immunol. 2003 May;111(5):913-21.

10. Schrör K. Aspirin and Reye syndrome: a review of the evidence. Paediatr Drugs. 2007;9(3):195-204.

11. Boysen G. Bleeding complications in secondary stroke prevention by antiplatelet therapy: a benefit-risk analysis. J Intern Med. 1999 Sep;246(3):239-45.

12. Fournier JP, Sommet A, Durrieu G, et al. Drug interactions between antihypertensive drugs and non-steroidal antiinflammatory agents: a descriptive study using the French
Pharmacovigilance database. Fundam Clin Pharmacol. 2014 Apr;28(2):230-5.

13. Salerno SM, Jackson JL, Berbano EP. Effect of oral pseudoephedrine on blood pressure and heart rate: a metaanalysis. Arch Intern Med. 2005 Aug 8-22;165(15):1686-94.

14. Lin JH, Cocchetto DM, Duggan DE. Protein binding as a primary determinant of the clinical pharmacokinetic properties of non-steroidal anti-inflammatory drugs. Clin Pharmacokinet. 1987 Jun;12(6):402-32.

15. Larsen LC, Fuller SH. Management of acetaminophen toxicity. Am Fam Physician. 1996 Jan;53(1):185-90.

16. Myers RP, Shaheen AA. Hepatitis C, alcohol abuse, and unintentional overdoses are risk factors for acetaminophenrelated hepatotoxicity. Hepatology. 2009 Apr;49(4):1399-400

17.Ibáñez L, Vidal X, Ballarín E, et al. Population-based druginduced agranulocytosis. Arch Intern Med. $2005 \mathrm{Apr}$ 25;165(8):869-74.

18. Bramble MG, Suvakovic Z, Hungin AP. Detection of upper gastrointestinal cancer in patients taking antisecretory therapy prior to gastroscopy. Gut. 2000 Apr;46(4):464-7.

19. Mogoș T, Dondoi C, lacobini AE. A review of oxalosis. Romanian Journal of Diabetes Nutrition and Metabolic Diseases, 23.3 (2016): 307-312.

20. Castagnet S, Blasco H, Vourc'h P et al. Polyneuropathie chronique démyélinisante et hypervitaminose B6 [Chronic demyelinating polyneuropathy and $\mathrm{B} 6$ hypervitaminosis]. Rev Med Interne. 2010 Dec;31(12):e1-3.

21. Plecko B, Stöckler S. Vitamin B6 dependent seizures. Can J Neurol Sci. 2009 Aug;36 Suppl 2:S73-7.

22. Tran N. Effects of pyridoxal phosphate and L-dopapyridoxal phosphate on DOPA decarboxylase activity. Experientia. 1972 Sep 15;28(9):1021-2.

23. Bastos Maia S, Rolland Souza AS, Costa Caminha MF et al. Vitamin A and Pregnancy: A Narrative Review. Nutrients. 2019 Mar 22;11(3):681.

24. Lassi ZS, Salam RA, Haider BA, et al. Folic acid supplementation during pregnancy for maternal health and pregnancy outcomes. Cochrane Database Syst Rev. 2013 Mar 28;(3):CD006896. 